\title{
Prevalence and antimicrobial susceptibility profile of Salmonella and Shigella among food handlers working in food establishment at Hawassa city, Southern Ethiopia
}

Neja Awol ${ }^{1 *}$, Demiss Nigusse ${ }^{2}$ and Musa Ali ${ }^{2}$

\begin{abstract}
Objective: The aim of this study was to determine the prevalence of Salmonella and Shigella, antibiotic susceptibility profile and associated factors among food handlers working in food establishment from June to December 2018 at Hawassa city, Southern Ethiopia.

Results: Out of the 236 food handlers screened for stool culture, 5 (2.12\%) were positive for Salmonella species and all of them were negative for Shigella species. All Salmonella species isolated were susceptible to ciprofloxacin and ceftriaxone but among the five isolated Salmonella species, 4 (80\%), 3 (60\%), 2 (40\%), 2 (40\%), and 2 (40\%) were resistant to tetracycline, ampicillin, amoxicillin-clavulanic acid, cotrimoxazole, and chloramphenicol respectively. Only food handlers hand washing the habit after toilet had a significant association with the prevalence of Salmonella species $(P=0.03)$.
\end{abstract}

Keywords: Food handlers, Prevalence, Antibiotic susceptibility, Salmonella, Shigella, Hawassa, Ethiopia

\section{Introduction}

Food-borne disease (FBD) remains a major public health problem across the globe. Several reports have shown that poor personal hygiene and handling of food stuffs could lead to various illnesses. Center for Disease Control and Prevention (CDC) identified more than 400 food-related infections, among which $20 \%$ are due to food handlers [1]. The spread of disease through food handlers is a common and persistent problem worldwide and food handlers may be carrying a wide range of enteric pathogen and have implicated in the transmission of many infections to the public [2].

The FBD is defined as diseases that are generally either infectious or toxic in nature and caused by the agents that enter the body through the ingestion of food [3]. The

*Correspondence: nejaawol2@gmail.com

${ }^{1}$ Worabe Comprehensive Specialized Hospital, Silte Zone, Worabe, Ethiopia

Full list of author information is available at the end of the article main causes of FBDs are bacteria (66\%), chemicals (26\%), virus (4\%) and parasites $(4 \%)[4,5]$.

Food-borne diseases are a serious threat to people in Africa, causing an unbearable public health burden and massive economic losses [6]. From the World Health Organization (WHO) reports, more than 91 million people in Africa region fall ill each year from FBD; resulting in 137,000 deaths. Diarrheal diseases are responsible for $70 \%$ of the burden of FBDs in the region, particularly non-typhoidal Salmonella, E. coli, and Food-borne cholera [7]. In developing countries, $70 \%$ of cases of diarrheal disease are associated with the consumption of contaminated food [8].

A food handler is anyone who works in a food and drink establishments and who handles food/have contact with any equipment or utensils that are likely to be in contact with food, such as plates, or chopping boards [9]. Food handlers who harbor and excrete entero-pathogenic bacteria may contaminate foods from their feces via their fingers, then to the food processing, and finally to healthy individuals [10]. 
There are more than 250 different FBDs in the world and most are caused by a variety of bacteria, viruses, and parasites. Food and water can be contaminated by bacteria such as Salmonella, Campylobacter, Listeria, pathogenic Escherichia coli, Yersinia, Shigella, Enterobacter, and Citrobacter $[11,12]$.

National Hygiene and Sanitation Strategy program reported that about $60 \%$ of the disease burden is related to poor hygiene and sanitation in Ethiopia. According to patient morbidity statistics (Hospitals and Health centers) of selected food-borne and food-related cases, the annual incidence of food-borne illnesses in Ethiopia ranged from 3.4 to $9.3 \%$, the median being $5.8 \%$ for the years $1985 / 86$ to $1989 / 90[13,14]$.

The aim of the current study was to determine the prevalence and antimicrobial susceptibility profile of Salmonella and Shigella species among food handlers working in food establishments at Hawassa city, Southern Ethiopia.

\section{Main text \\ Methods \\ Study area}

Hawassa is the capital city of Southern Nations Nationalities and Peoples Region (SNNPR) which is located on the shores of Lake Hawassa in the Great Rift Valley and located 275 to south of Addis Ababa, a capital city of Ethiopia. The Ethiopian Central Statistical Agency (CSA 2007), gives the estimated population of Hawassa for 2007 as 259,803 .

\section{Study design and study period}

A community-based cross-sectional study was conducted from June to December 2018 among food handlers working in food establishments at Hawassa city, Southern Ethiopia.

\section{Sample size determination}

The sample size was calculated by using a single population proportion formula.

$$
\mathrm{n}=\mathrm{Z}^{2} \times \mathrm{P} \times(1-\mathrm{P}) / \mathrm{D}^{2}
$$

where $\mathrm{n}$ is the sample size; $\mathrm{Z}$ is the reliability coefficient (confidence level) which is $95 \%=1.96, \mathrm{P}$ is the anticipated population proportion, D is the margin of error, which is $4 \%=0.04$.

By using the anticipated population proportion of $10 \%$ from a study in Arba Minch, South Ethiopia [15],

$$
\mathrm{n}=1.96^{2} \times(0.1) \times(1-0.1) / 0.04^{2}=217,
$$

after adding $10 \%$ of non-respondents the final sample size was $=217+22=239$.

\section{Sampling technique}

Simple random sampling technique was used to select the 120 food establishments among the 358 licensed food establishments found in the Hawassa city. From each food establishments, two food handlers were selected by simple random sampling technique.

\section{Data collection procedure}

Data related to socio-demographic characteristics, hand washing habit, and food safety practices of food handlers were collected by face-to-face interview using pre-tested structured questionnaire and by observation.

\section{Sample collection, transport and processing}

Stool samples were collected in labeled, clean, dry and leak-proof cups. The specimens were immediately placed on to Cary-Blair transport medium using swabs and transported in ice- packed box to SNNPR, Hawassa public health regional laboratory.

About $1 \mathrm{~g}$ of stool sample was directly inoculated on to MacConkey (MAC) and xylose-lysine-deoxycholate (XLD) agar plates by using a sterile wire loop. The inoculated culture media were incubated at $37{ }^{\circ} \mathrm{C}$ for 18-24 $\mathrm{h}$ and examined for colony characteristics of Salmonella/Shigella species. The growths of suspected colonies of Salmonella/Shigella species were detected by their characteristic appearance on MAC agar (nonlactose fermenter, smooth, colorless to yellow colonies, sometimes with black centered) and on XLD agar (small pin to red colonies and black-centered colonies [16].

For further confirmation, typical and suspected colonies of Salmonella/Shigella were selected and streaked onto the surface of nutrient agar. Colonies were picked from the streaked nutrient agar and inoculated into Triple Sugar Iron (TSI) agar, Simmon's citrate agar, urea broth, hydrogen sulfide $(\mathrm{H} 2 \mathrm{~S})$ production, indole production and motility in Sulfide-Indole-Motility (SIM) medium and incubated for $24 \mathrm{~h}$ at $37^{\circ} \mathrm{C}$ [17]. Colonies producing an alkaline slant (red color) with acid butt (yellow color) on TSI with H2S, positive for lysine (purple color), positive for citrate utilization, positive for motility, negative for urea hydrolysis (red color) and negative for tryptophan utilization (indole test) (yellow-brown ring) were considered to be Salmonella species.

\section{Antimicrobial susceptibility testing}

Antimicrobial susceptibility test was determined by using disc diffusion method [17]. Briefly, pure identified colonies from the overnight culture were suspended in nutrient broth and incubated for $4 \mathrm{~h}$ at $37{ }^{\circ} \mathrm{C}$. Turbidity of broth culture was checked against $0.5 \mathrm{McF}$ arland standards. By using sterile cotton swab the organism in 
the broth was uniformly inoculated onto Mueller-Hinton Agar. The antimicrobial agents used for the isolates were amoxicillin-clavulanic acid $(30 \mu \mathrm{g})$, ampicillin $(10 \mu \mathrm{g})$, chloramphenicol $(30 \mu \mathrm{g})$, ciprofloxacin $(5 \mu \mathrm{g})$, ceftriaxone $(30 \mu \mathrm{g})$, nalidixic acid $(30 \mu \mathrm{g})$, tetracycline $(30 \mu \mathrm{g})$ and cotrimoxazole $(25 \mu \mathrm{g})$. The zones of inhibition were read and results were examined for the diameter of growth inhibition around the discs and interpreted as sensitive, intermediate or resistant according to CLSI, 2018 guideline [18].

\section{Data management and quality control}

The qualities of data were assured by proper designing and pre-testing of the questionnaires. The questionnaire was pre-tested on $5 \%$ of the sample at Hawassa University main campus) who are not included in the study. As quality control, E. coli (ATCC 25922) was used. Sterility of culture media was checked by incubating $5 \%$ of the batch at $35{ }^{\circ} \mathrm{C}$ overnight and was observed for bacterial growth.

\section{Data processing and analysis}

Data were entered, cleaned, coded and analyzed using statistical package for social science (SPSS) version 23. Data were organized, summarized, and presented in descriptive statistical methods. A $P$-value of $\leq 0.05$ was considered as statistically significant association between the factors and Salmonella/Shigella species by using Chisquare/Fishers test.

\section{Results}

\section{Sociodemographic characteristics}

A total of 236 food handlers serving in food establishments found in Hawassa city participated in the current study with a response rate of $98.75 \%$. Of these, $150(63.6 \%)$ were females and the mean age was 23.8 years \pm 10.48 . Majority 125 (53\%) of the study participants were in the age group between 21 and 30 years. Of the total participants 157 (66.5\%) were served as cookers.

Out of the total study participants 178 (75.4\%), 84 (35.6\%), 162 (68.6\%), 88 (37.3\%) washed their hands with water and soap before touching food, after touching dirty materials, and after touching body parts respectively. Eighty-eight (37.3\%) of participants attended medical checkup (Table 1).

\section{Prevalence of Shigella and Salmonella}

Among 236 food handlers participated in the current study, 5 (2.1\%) were positive for Salmonella species, while no Shigella species were isolated from the stool samples.
Factors associated with the prevalence of Salmonella species among food handlers

Among different variables assessed in this study, only washing hands after toilet was significantly associated with prevalence of Salmonella species (Table 2).

\section{Antimicrobial susceptibility test of Salmonella species}

Out of five Salmonella species 4 (80\%), 3 (60\%), 2 (40\%) were resistant to tetracycline, ampicillin, and cotrimoxazole respectively (Table 3 ).

\section{Discussion}

In the present study, from the total 236 food handlers $5(2.1 \%)$ of them were positive for Salmonella species which is in line with the findings from Bahir Dar, Northern Ethiopia (2.7\%) [19], Ghana (2.3\%) [20] and Gondar, Ethiopia (1.3\%) [21]. However, the prevalence of Salmonella species in the present study is lower than the prevalence reported from Nigeria $(5.5-17 \%)[22$, 23], Arba Minch, Southern Ethiopia (6.9\%) [15], Saudi Arabia (3.86\%) [24] and Haramaya, Eastern Ethiopia (3.6\%) [25]. The finding of current study is high compared to report from Hawassa, Ethiopia [26], Gondar, Ethiopia [27], Makah, Saudi Arabia [28], Jordan [29], Thailand [30], Japan [31], Dilla, Southern Ethiopia [32] and Nigeria [2]. The difference in the prevalence of Salmonella species among food handlers observed across different countries and within in country may be due to laboratory methods used, level of education, economic status, and characteristics of study participants.

In the present study no Shigella species were recovered from the stool culture which is similar with the results from Addis Ababa [33], Saudi Arabia [28] and Jordan [29]. However, $0.4 \%, 3.1 \%, 1.4 \%$ and $0.9 \%$ prevalence of Shigella species were reported from Hawassa, Ethiopia [26], Gondar, Ethiopia [27], Haramaya, Eastern Ethiopia [25] and Iran [34] respectively. The prevalence of Shigella among food handlers in a community may vary according to geographical region. These differences might be due to the higher standards of education, differences in geographical variation and socio-demographic characteristics of the study population.

In the present study food handlers' hand washing practices after toilet with soap and water was $68.6 \%$ which is in line with the findings from Gondar (63.3\%) [35] and Nigeria (71.9\%) [36]. However, it is low compared to a report from Jimma (77\%) [37] and Addis Ababa (80.8\%) [33]. and it is high compared to report from Arba Minch (56.4\%) [15]. Compared to finding from Jimma (57\%) [37], high proportion of food handlers $(75.4 \%)$ in this 
Table 1 Hand washing and food safety practices of food handlers working at Hawassa city, Southern Ethiopia, June to December $2018(\mathrm{~N}=236)$

\begin{tabular}{|c|c|c|c|}
\hline Variables & Category & Frequency & Percent \\
\hline \multirow[t]{2}{*}{ Wash hand before touching food } & With water and soap & 178 & 75.4 \\
\hline & Only with water & 58 & 24.6 \\
\hline \multirow[t]{3}{*}{ Wash hand after touching dirty materials } & With water and soap & 84 & 35.6 \\
\hline & Only with water & 120 & 50.8 \\
\hline & Not wash at all & 32 & 13.6 \\
\hline \multirow[t]{3}{*}{ Wash hand after touching body parts } & With soap and water & 38 & 16.1 \\
\hline & Only with water & 32 & 13.6 \\
\hline & Not at all & 166 & 70.3 \\
\hline \multirow[t]{2}{*}{ Wash hand after toilet } & With soap and water & 162 & 68.6 \\
\hline & Only with water & 74 & 31.4 \\
\hline \multirow[t]{2}{*}{ Use hand glove } & Yes & 13 & 5.5 \\
\hline & No & 223 & 94.5 \\
\hline \multirow[t]{2}{*}{ Attend medical checkup } & Yes & 88 & 37.3 \\
\hline & No & 148 & 62.7 \\
\hline \multirow[t]{2}{*}{ Wear hair cover } & Yes & 91 & 38.6 \\
\hline & No & 145 & 61.4 \\
\hline \multirow[t]{2}{*}{ Wear gown or coat } & Yes & 194 & 82.2 \\
\hline & No & 42 & 17.8 \\
\hline \multirow[t]{2}{*}{ Gown or coat clean } & Yes & 101 & 42.8 \\
\hline & No & 135 & 57.2 \\
\hline \multirow[t]{2}{*}{ Finger nails trimmed } & Yes & 147 & 62.3 \\
\hline & No & 89 & 37.7 \\
\hline \multirow[t]{2}{*}{ Painted nail } & Yes & 21 & 8.9 \\
\hline & No & 215 & 91.1 \\
\hline \multirow[t]{2}{*}{ Wear jewelry } & Yes & 54 & 22.9 \\
\hline & No & 182 & 77.1 \\
\hline
\end{tabular}

study had a habit of washing with water and soap before touching food.

Based on the present study, $62.3 \%$ of food handlers keep their fingernail trimmed which is lower compared to report from Jimma, Ethiopia (80.4\%) [37] but a comparable finding was reported from Nigeria (69.1\%) [23]. Unlike the current study, (8.9\%), high proportion of study participants from Bahr Dar (21.8\%) [38] and Jimma 969.6\%) [37] received training on 'food handling and preparation.' The proportion food handlers who had worn appropriate hair cover found in this study (38.6\%) is similar with report from Jimma (40.4\%) [37]. Moreover, proportion of food handlers who had worn protective coat in this study (82.2\%) is comparable with finding from North West Ethiopia (88.7\%) [39]. In this study, 37.3\% of food handlers had medical checkup, this finding is lower than report from Bahir Dar, Ethiopia (83.5\%) and Jimma, Ethiopia (57\%) [19, 37].

In this study, hand washing habit and food handling practices were found unsatisfactory. Therefore, it is preferable to combine proper hand washing with the other food hygienic practices in order to prevent food contamination. In general only food handlers hand washing habit after toilet had a significant association with the prevalence of Salmonella species $(P=0.03)$ which is similar with the study in Arba Minch, South Ethiopia [15]; however, a study in Addis Ababa, Ethiopia found no significant association between the prevalence of Salmonella and hand washing habit after toilet [33].

In this study $80 \%$ of the isolated Salmonella species were resistant to tetracycline which is high compared to study from Gondar (46.2\%) [39]. The resistance profile to cotrimoxazole and chloramphenicol is comparable with the study done in Debre Markos, Ethiopia [40]. Sixty percent and 20\% of isolated Salmonella species were resistant to ampicillin and nalidixic acid respectively which is similar with the report from Gondar, Ethiopia [35] but higher resistance to ampicillin was reported from Addis Ababa and Debre Markos [33, 40]. These differences might be due to the low number of isolates in our study, geographical differences and study population. 
Table 2 Association of Salmonella species with socio-demographic factors, hand washing habit and food safety practices of food handlers at Hawassa city, Southern Ethiopia, June to December $2018(\mathrm{~N}=236)$

\begin{tabular}{|c|c|c|c|c|c|}
\hline \multirow[t]{2}{*}{ Variables } & \multirow[t]{2}{*}{ Categories } & \multicolumn{3}{|c|}{ Salmonella species $(\mathrm{n}=5)$} & \multirow[t]{2}{*}{$P$ value } \\
\hline & & Positive n (\%) & Negative $\mathrm{n}(\%)$ & Total & \\
\hline \multirow[t]{2}{*}{ Gender } & Male & $1(1.2)$ & $85(98.8)$ & 86 & 0.322 \\
\hline & Female & $4(2.7)$ & $146(97.3)$ & 150 & \\
\hline \multirow[t]{2}{*}{ Educational status } & Illiterate & - & $20(100)$ & 20 & 0.492 \\
\hline & Literate & $5(2.3)$ & $211(97.7)$ & 216 & \\
\hline \multirow[t]{2}{*}{ Trained on food preparation } & Yes & - & $21(100)$ & 21 & 1.00 \\
\hline & No & $5(2.3)$ & $210(97.7)$ & 215 & \\
\hline \multirow{2}{*}{ Washed hand before touching food } & Soap and water & $2(1.1)$ & $176(98.9)$ & 178 & 0.097 \\
\hline & Water only & $3(5.2)$ & $55(94.8)$ & 58 & \\
\hline \multirow[t]{2}{*}{ Washed hand after toilet } & Soap and water & - & $162(100)$ & 162 & 0.03 \\
\hline & Water only & $5(6.8)$ & $69(93.2)$ & 74 & \\
\hline \multirow[t]{2}{*}{ Medical checkup } & Yes & $1(1.1)$ & $87(98.9)$ & 88 & 0.653 \\
\hline & No & $4(2.7)$ & $144(97.3)$ & 148 & \\
\hline \multirow[t]{2}{*}{ Worn hair cover } & Yes & $1(1.1)$ & $91(98.9)$ & 92 & 0.651 \\
\hline & No & $4(2.8)$ & $140(97.2)$ & 144 & \\
\hline \multirow[t]{2}{*}{ Worn gown or coat } & Yes & $5(2.6)$ & $189(97.4)$ & 194 & 0.589 \\
\hline & No & - & $42(100)$ & 42 & \\
\hline \multirow[t]{2}{*}{ Trimmed finger nails } & Yes & $2(1.4)$ & $145(98.6)$ & 147 & 0.368 \\
\hline & No & $3(3.4)$ & $86(96.6)$ & 89 & \\
\hline \multirow[t]{2}{*}{ Worn jewelry } & Yes & $2(3.7)$ & $52(96.3)$ & 54 & 0.322 \\
\hline & No & $3(1.6)$ & 179 (98.4) & 182 & \\
\hline \multirow[t]{2}{*}{ Use hand glove } & Yes & $1(7.7)$ & $12(92.3)$ & 13 & 0.249 \\
\hline & No & $4(1.8)$ & $219(98.2)$ & 223 & \\
\hline \multirow[t]{3}{*}{ Wash hand after touching body parts } & Soap and water & - & $38(100)$ & 38 & 0.593 \\
\hline & Water only & $1(3.1)$ & $31(96.9)$ & 32 & \\
\hline & No & $4(2.4)$ & $162(97.6)$ & 166 & \\
\hline \multirow[t]{3}{*}{ Wash hand after touching dirty materials } & Soap and water & - & $84(100)$ & 84 & 0.085 \\
\hline & Water only & $5(4.2)$ & $115(95.8)$ & 120 & \\
\hline & No & - & $32(100)$ & 32 & \\
\hline
\end{tabular}

Table 3 Antimicrobial sensitivity patterns of Salmonella species isolates from selected food handlers in Hawassa city, South Ethiopia June to December 2018

\begin{tabular}{llll}
\hline Antibiotics & $\begin{array}{l}\text { Susceptible } \\
\mathbf{n}(\%)\end{array}$ & $\begin{array}{l}\text { Intermediate } \\
\mathbf{n}(\%)\end{array}$ & $\begin{array}{l}\text { Resistant } \\
\mathbf{n}(\%)\end{array}$ \\
\hline Ciprofloxacin & $5(100)$ & - & - \\
Tetracycline & $1(20)$ & - & $4(80)$ \\
Ampicillin & $2(40)$ & - & $3(60)$ \\
Amoxicillin/clavulanic acid & $2(40)$ & $1(20)$ & $2(40)$ \\
Ceftriaxone & $5(100)$ & - & - \\
Cotrimoxazole & $3(60)$ & - & $2(40)$ \\
Chloramphenicol & $2(40)$ & $1(20)$ & $2(40)$ \\
Nalidixic acid & $4(80)$ & - & $1(20)$ \\
\hline
\end{tabular}

All the isolated Salmonella species were susceptible to ciprofloxacin, and ceftriaxone which are consistent with the study conducted in Nigeria, Jimma, Arba Minch, Debre Markos and Addis Ababa [15, 22, 35, 40-42].

\section{Limitation}

The present study had limited to serotype the isolated Salmonella species due to the scarcity of financial and reagents constraints. Using $\mathrm{H} 2 \mathrm{~S}$ negative as one criterion may have caused false negative as some Salmonella are $\mathrm{H} 2 \mathrm{~S}$ producer.

\footnotetext{
Abbreviations

CDC: Center for Disease Control and Prevention; CLSI: Clinical Laboratory Standard Institute; CSA: Central Statistical Agency; FBDs: food-borne diseases; WHO: World Health Organization; MAC: MacConkey; MHA: Muller Hinton Agar; SNNPR: Southern Nations Nationalities and Peoples Region; TSI: Triple Sugar Iron; XLD: xylose-lysine-deoxycholate.
} 


\section{Acknowledgements}

We would like to acknowledge Hawassa University College of Medicine and Health sciences for supporting the study. We also acknowledge all the study participants for their willing to take part in the study.

\section{Authors' contributions}

NA: Conceived, designed the experiments, laboratory work, data analysis and write up DN: review, supervision, analysis and manuscript preparation MA: review, supervision, analysis and manuscript preparation. All authors read and approved the final manuscript.

\section{Funding}

The current study was supported by Hawassa University, College of Medicine and Health Sciences and South Nation and Nationalities Regional public Health Laboratory. The support included payment for data collectors and materials and supplies required for the study. The support did not include designing of the study, analysis and interpretation of the data and manuscript writing.

\section{Availability of data and materials}

The datasets used and analyzed during the current study available from the corresponding author on reasonable request.

\section{Ethics approval and consent to participate}

This study was ethically cleared b Institutional Review Board (IRB) of the College of Medicine and Health Sciences, Hawassa University (Reference number: IRB/158/10). Permission was obtained from Hawassa city health office and owner/manager of the food establishments. Written informed consent was obtained from each study participant.

\section{Consent for publication}

Not applicable.

\section{Competing interests}

The authors declare that they have no competing interests.

\section{Author details}

${ }^{1}$ Worabe Comprehensive Specialized Hospital, Silte Zone, Worabe, Ethiopia.

2 School of Medical Laboratory Science, College of Medicine and Health Science, Hawassa University, Hawassa, Ethiopia.

Received: 27 May 2019 Accepted: 12 October 2019

Published online: 30 October 2019

\section{References}

1. Ali R, Hayat A, Fatima M, Noman M. Detection and enumeration of Enteric bacteria associated with food handlers and surfaces of food manufacturing industry located in Hub city, Pakistan. World Scientific News. 2016:48:192-203.

2. Umo AN, Okon AO. Asymptomatic carriers of enteric pathogens and the risk factors among food handlers in a rural setting in Nigeria. J Adv Microbiol. 2017;4(3):1-6.

3. World Health Organization Regional Office for Africa Brazzaville. Manual for integrated foodborne disease surveillance in the WHO African region. Geneva: World Health Organization; 2012.

4. Addis M, Sisay D. A review on major food borne bacterial illnesses. J Trop Dis. 2015;3(4):176-83.

5. Neme K, Hailu B, Belachew T. Assess sanitary condition and food handling practices of restaurants in Jimma Town, Ethiopia: implication for food born infection and food intoxication. Food Sci Qual Manag. 2017;60.

6. National Food Safety Systems in Africa. A situation analysis Harare, Zimbabwe. In: FAO/WHO Regional Conference on Food Safety for Africa; 2005.

7. World Health Organization. Burden of Foodborne Diseases in WHO African Region. Food safety newsletter. 2016;3(3)

8. Zeru K, Kumie A. Sanitary conditions of food establishments in Mekelle town, Tigray, North Ethiopia. Ethiop J Health Dev. 2007;21(1):3-11.

9. Scallan EHR, Angulo FJ, Tauxe RV, Widdowson M-A, Roy SL, Jones JL. GP: foodborne illnesses acquired in the United States-major pathogens. Emerg Infect Dis. 2011;17(1):7-15.
10. Kaferstein F, Abdussalam M. Food safety in the 21 st century. Bull World Health Organ. 1999;77(4):347-51.

11. CDC. CDC: food borne illness report-United States, Annual report 2005. http://www.cdc.gov/ncidod/dbmd/diseaseinfo/files/foodborne_illne ss_faq.pdf. Accessed 10 Jan 2005.

12. Tan SL, Lee HY, AbuBakar F, AbdulKarim MS, Rukayadi Y, Mahyudin NA. Microbiological quality on food handlers' hands at primary schools in Hulu Langat District, Malaysia. Int Food Res J. 2013;20(5):2973-7.

13. Kalekidan T, Behailu K, Rediet $H$. The Ethiopian perception on food safety system. Adv Food Sci Technol. 2014;2(9):260-8.

14. Ayana Z, Yohannis M, Abera Z. Food-borne bacterial diseases in Ethiopia. Acad J Nutr. 2015;4(1):62-76.

15. Mama M, Alemu G. Prevalence, antimicrobial susceptibility patterns and associated risk factors of Shigella and Salmonella among food handlers in Arba Minch University, South Ethiopia. BMC Infect Dis. 2016;16:686.

16. Cheesbrough M. District laboratory practice in tropical countries part 2. 2nd ed. New York: United States of America by Cambridge University Press; 2006.

17. Vandepitte J, Verhaegen J, Engbaek K, Rohner P, Piot P, Heuck CC. Basic laboratory procedures in clinical bacteriology. 2nd ed. Geneva: World Health Organization; 2003.

18. Clinical and Laboratory Standards Institute (CLSI). Performance standards for antimicrobial susceptibility testing, 28th ed. CLSI supplement M100S; 2018

19. Abera B, Yitayew G, Amare H. Salmonella serotype Typhi, Shigella, and intestinal parasites among food handlers at Bahir Dar University, Ethiopia. J Infect Dev Ctries. 2016;10(2):121-6.

20. Feglo PK, Frimpong EH, EsselL-Ahun M. Salmonellae carrier status of food vendors in Kumasi, Ghana. East Afr Med J. 2004;81:358-61.

21. Dagnew M, Tiruneh M, Moges F, Gizachew M. Bacterial profile and antimicrobial susceptibility pattern among food handlers at Gondar University Cafeteria, Northwest Ethiopia. J Infect Dis Ther. 2013;1(2):1-6.

22. Smith SI, Bamidele M, Goodluck HA, Rowora MN, Omonigbehn EA, Opere $\mathrm{BO}$, et al. Antimicrobial susceptibilities of Salmonellae isolated from foodhandlers and cattle in Lagos, Nigeria. Int J Health Res. 2009;2(2):189-93.

23. Mobolaji OA, Olubunmi OF. Assessment of the hygienic practices and the incidence of enteric bacteria in food handlers in small businesses in an urban area in Abeokuta. Int Res J Microbiol. 2014;5(3):41-9.

24. Al-Ghamd KS. Parasitic and bacterial infestation among food handlers in Jubail, Eastern region of Saudi Arabia. J Fam Community Med. 1996;3(2):64.

25. Marami D, Hailu K, Tolera M. Prevalence and antimicrobial susceptibility pattern of Salmonella and Shigella species among asymptomatic food handlers working in Haramaya University cafeterias, Eastern Ethiopia. BMC Res Notes. 2018;11:74.

26. Desta M, Asrat D, Weldeamanuel Y, Nigusie D. Prevalence of intestinal parasites and Salmonella and Shigella among food handlers at food service establishments in the main campus and Health Sciences College of Hawassa University, Hawassa, Ethiopia. Ethiop J Health Dev. 2014;28(1):29-34

27. Andargie G, Kassu A, Moges F, Tiruneh M, Huruy K. Prevalence of Bacteria and Intestinal Parasites among Foodhandlers in Gondar Town, Northwest Ethiopia. J Health Popul Nutr. 2008;26(4):451.

28. Zaglool DA, Khodar YA, Othman RA, Farooq MU. Prevalence of intestinal parasites and bacteria among food handlers in a tertiary care hospital. Niger Med J. 2011;52(4):266.

29. Abdel-Dayem M, Zoubi RA, Hani RB, Amr ZS. Microbiological and parasitological investigation among food handlers in hotels in the Dead Sea area, Jordan. J Microbiol Immunol Infect. 2014;47:377-80.

30. Kusolsuk T, Maipanich W, Nuamtanong S, Pubampen S, Sa-nguankiat S, Rojekittikhun W, et al. Parasitic and enteric bacterial infections among food handlers in tourist-area restaurants and educational-institution Cafeterias, Sai-Yok District, Kanchanaburi Province, Thailand. J Trop Med Parasitol. 2011;34(2):49-53.

31. Murakami K, Ishihara T, Horikawa K, Oda T. Features of Salmonella serovars among food handlers in Kyushu, Japan. N Microbiol. 2007;30:155-9.

32. Birhaneselassie M, Williams D. A study of Salmonella carriage among asymptomatic food-handlers in southern Ethiopia. Int J Nutr Food Sci. 2013:2(5):243-5. 
33. Aklilu A, Kahase D, Dessalegn M, Tarekegn N, Gebremichael S, Zenebe S, et al. Prevalence of intestinal parasites, Salmonella and Shigella among apparently health food handlers of Addis Ababa University student's cafeteria, Addis Ababa, Ethiopia. BMC Res Notes. 2015;8:17.

34. Dahiru JY, Abubakar FA, Idris H, Abdullahi SA. Bacterial Contamination of Food Handlers at Various Restaurants in Kano State Metropolis, Kano Nigeria. Int J Curr Microbiol Appl Sci. 2016;5(5):165-70.

35. Garedew-Kifelew L, Wondafrash N, Feleke A. Identification of drug-resistant Salmonella from food handlers at the University of Gondar, Ethiopia. BMC Res Notes. 2014;7:545.

36. Smith SI, Agomo CO, Bamidele M, Opere BO, Aboaba OO. Survey of food handlers in bukas (a type of local restaurant) in Lagos, Nigeria about typhoid fever. HEALTH. 2010;2(8):951-6.

37. Assefa T, Tasew H, Wondafrash B, Beker J. Contamination of Bacteria and Associated Factors among Food Handlers Working in the Student Cafeterias of Jimma University Main Campus, Jimma, South West Ethiopia. Altern Integr Med. 2015;4:1.

38. Kibret M, Abera B. The sanitary conditions of food service establishments and food safety knowledge and practices of food handlers in Bahir Dar town. Ethiop J Health Sci. 2012;22(1):27-35.
39. Tessema AG, Gelaye KA, Chercos DH. Factors affecting food handling Practices among food handlers of Dangila town food and drink establishments, North West Ethiopia. BMC Public Health. 2014;14:571.

40. Mengist A, Mengistu G, Reta A. Prevalence and antimicrobial susceptibility pattern of Salmonella and Shigella among food handlers in catering establishments at Debre Markos University, Northwest Ethiopia. Int J Infect Dis. 2018;75:74-9.

41. Addis Z, Kebede N, Worku Z, Gezahegn H, Yirsaw A, Kassa T. Prevalence and antimicrobial resistance of Salmonella isolated from lactating cows and in contact humans in dairy farms of Addis Ababa: a cross sectional study. BMC Infect Dis. 2011;11:222.

42. Worku T, Jejaw A, Kannan S, Wondafrash B. Isolation and Antimicrobial Sensitivity Patterns of Enteric Bacterial Pathogens from Asymptomatic Food Handlers, Jimma, Ethiopia. Am J Health Res. 2015;3(6):399-406.

\section{Publisher's Note}

Springer Nature remains neutral with regard to jurisdictional claims in published maps and institutional affiliations.
Ready to submit your research? Choose BMC and benefit from:

- fast, convenient online submission

- thorough peer review by experienced researchers in your field

- rapid publication on acceptance

- support for research data, including large and complex data types

- gold Open Access which fosters wider collaboration and increased citations

- maximum visibility for your research: over $100 \mathrm{M}$ website views per year

At BMC, research is always in progress.

Learn more biomedcentral.com/submissions 